\title{
The Main Infrastructure for Better Dental Implant Management: A Systematic Review on Dental Implant Registries
}

Roya Naemi(Former Corresponding Author)

Tehran University of Medical Sciences https://orcid.org/0000-0002-3943-7053

Hamid Reza Barikani

Tehran University of Medical Sciences

Leila Shahmoradi(New Corresponding Author) ( $\sim$ Lshahmoradi@tums.ac.ir )

Research article

Keywords: Dental implants, Tooth implants, Registry system, Registries, Implant registry

Posted Date: November 28th, 2019

DOI: https://doi.org/10.21203/rs.2.16487/v2

License: (c) (i) This work is licensed under a Creative Commons Attribution 4.0 International License. Read Full License 
The authors have withdrawn this preprint from Research Square 